\title{
EFFECT OF SHADING AND HYDROTHERMAL AGING ON OPTICAL PROPERTIES OF PARTIALLY AND FULLY STABILIZED ZIRCONIA
}

\author{
Marwa Mahmoud Abdel Latif*, Gehan Abdel-Monem El-Olimy ${ }^{* *}$ and Manal Ahmed Elebiary ${ }^{* * *}$
}

\begin{abstract}
Statement of problem: Zirconia undergoes phase transformation due to low temperature degradation LTD which could deteriorate its optical properties.

Objectives: Current study was conducted to evaluate the effect of shading and hydrothermal aging on optical properties of partially and fully stabilized zirconia.

Materials and methods: Two commercially available zirconia products, high-translucent PSZ (Prettau ${ }^{\circledR}$, Zirkonzahn) and ultra-translucent FSZ (Prettau ${ }^{\circledR}$, Anterior, Zirkonzahn) were assessed. 80 disc shaped specimens $(12 \times 1 \mathrm{~mm})$ were prepared; half of the specimens were shaded using acid-free coloring solution. Half of the specimens were subjected to accelerated hydrothermal aging using autoclave $\left(134^{\circ} \mathrm{c}\right.$ at $\left.2 \mathrm{MPa}\right)$ for 5 hours. The specimens were divided into 4 subgroups. Non-shaded, non-aged (control), (non-shaded, aged group), (shaded, non-aged group) and (shaded, aged group). Contrast ratio CR and translucency parameter TP were evaluated in each subgroup using reflective spectrophotometer. X-ray diffraction analysis was used to measure the amount of tetragonal-monoclinic phase transformation. Microstructural analysis was evaluated using atomic force microscope. SPSS program was used to evaluate the data $(\mathrm{P} \leq 0.05)$.
\end{abstract}

Results: FSZ recorded higher translucency parameter and lower contrast ratio than PSZ; which were significantly affected by shading and aging in all subgroups except for non-shaded aged subgroups of PSZ.

Conclusions: Shading and hydrothermal aging induced tetragonal to monoclinic transformation in PSZ and FSZ which lead to changes in their optical properties.

KEYWORDS: Monolithic Zirconia, Hydrothermal Aging, Shading, Contrast Ratio, Translucency Parameter.

\footnotetext{
* Dental Biomaterials Department, Tanta University

** Biomaterials, Faculty of Dentistry, Tanta University

*** Head of the Dental Biomaterials Department, Faculty of Dentistry, Tanta University
} 


\section{INTRODUCTION}

Zirconia is a common dental ceramic that meets patients' demand for metal-free restorations. Yttriastabilized tetragonal zirconia polycrystals (Y-TZP) have been widely used in dentistry for crowns and partial fixed prostheses as a core material to support more aesthetic ceramic material. However, there is a relatively high rates of delamination or chipping of porcelain. In order to solve this problem, efforts have been made to develop a monolithic Y-TZP (also known as full-contour Y-TZP) with improved optical properties, which would dispense with the need for porcelain veneers ${ }^{[1,2]}$.

Zirconia is a polymorphic material that can be found in three different crystalline forms cubic, tetragonal, and monoclinic; depending on various temperatures. The most desirable phase in dentistry is the tetragonal phase. Many oxides may be added to zirconia to stabilize the tetragonal phase at room temperature ${ }^{[3]}$. The concentration of the stabilizer plays a decisive role in the performance of zirconia. The addition of $2-3 \mathrm{~mol} \%$ of yttrium oxide results in partially stabilized zirconia (PSZ) at room temperature, which is the most attractive composition for "transformation toughening". Increasing yttria concentrations to no less than 8 mol $\%$ is needed to achieve fully stabilized zirconia (FSZ). Recently, some dental zirconia manufacturers have produced zirconia in its fully stabilized form in efforts to improve zirconia's translucency ${ }^{[4]}$.

The primary color of zirconia is white to ivory. Alloying with metal oxides in the dental laboratory, infiltrating the green-stage zirconia with specific coloring liquids is one of the approaches to obtain colored zirconia ${ }^{[5]}$. The use of these metal oxides can effectively modify the zirconia $\mathrm{L}^{*}, \mathrm{a}^{*}$, and $\mathrm{b}^{*}$ color parameters. Nevertheless, metal oxides may lead to crystallographic changes in the material, affecting other properties ${ }^{[6]}$.

The translucency of ceramic materials has been accentuated as one of the primary factors in prevailing the esthetic outcome of ceramic restorations [7]. Different strategies can be established in different commercial zirconia with a claimed improved translucency. One of them is introducing significant amounts of cubic phase, which is optically isotropic and does not induce birefringence like tetragonal phase ${ }^{[8]}$.

The main drawback of zirconia ceramics is their sensitivity to low temperature degradation (LTD) or aging that leads to tetragonal to monoclinic transformation and a degradation that starts on the surface and propagates into the bulk of the material, diminishing its mechanical properties due to volume changes, the transformed grains cause micro-cracks and the material becomes degraded ${ }^{[9]}$. This is of particular interest for dental zirconia ceramics, as their degradation in the oral environment due to the exposure to oral fluids and mechanical stress over prolonged periods of time. Furthermore, there is growing popularity of monolithic zirconia restorations where much larger areas of zirconia are in contact with the oral environment ${ }^{[10,11]}$.

Many studies have reported that the low temperature degradation LTD of stabilized zirconia causes a statistically significant decrease in flexural strength ${ }^{[12-14]}$. Additionally, tooth-colored Y-TZP ceramic has recently been reported to have a reduced flexural strength related to the tetragonal to monoclinic phase transformation ${ }^{[15-17]}$. As the same microstructure properties that causes certain mechanical properties to manifest in zirconia is also responsible for its optical properties. Thus, it's reasonable to conclude that LTD related changes in the microstructure that leads to changes in the mechanical properties would also affect their optical properties.

With claims of greater translucency properties regarding this monolithic zirconia ceramic material, Limited research has been published evaluating the translucency and the effects of hydrothermal degradation (LTD) and shading, Moreover, little knowledge is known about the effects of shading and aging on the rates of the tetragonal to monoclinic 
phase transformation and its effect on the optical properties. In this context, the objective of this work was to further explore the optical performance of partially stabilized PSZ zirconia versus fully stabilized FSZ zirconia whether these are influenced by aging (LTD) and/or shading.

The null hypothesis of this study was that shading and/or hydrothermal aging would not influence microstructure, crystallography, contrast ratio $\mathrm{CR}$ and translucency parameter TP of partially and fully stabilized zirconia.

\section{MATERIALS AND METHODS}

\section{Milling of zirconia cylinders}

Eighty-disc shaped specimens $(12 \times 1 \mathrm{~mm})$ were prepared from CAD/CAM pre-sintered blanks of high-translucent PSZ (Prettau ${ }^{\circledR}$, Zirkonzahn, Taufers, Italy) and ultra-translucent FSZ (Prettau $\AA$, Anterior, Zirkonzahn, Taufers, Italy). Half of the specimens were shaded using acid-free coloring solution. To evaluate the effect of low temperature degradation LTD; hydrothermal aging for the shaded and non-shaded specimens were applied. The specimens were divided into 4 subgroups $(n=10)$ Non-shaded, non-aged (control), (non-shaded, aged group), (shaded, non-aged group) and (shaded, aged group).

Cylinders were milled with an approximate 20\%-25\% oversize. Each blank was labeled with a barcode and a specific enlargement factor to calculate the exact oversize needed during milling to compensate for the sintering shrinkage. Milling of the cylinders was performed by a dental milling machine (Datron Dwx5, Datron AG, MuhltalTraisa, Germany) without water cooling.

\section{Cutting of zirconia discs}

The milled zirconia cylinder was fixed to a low speed water-cooled diamond saw (IsoMet Low Speed Saw, Buehler, Lake Bluff, IL, USA), in order to perform an accurate cutting procedure, the speed was maintained below $250 \mathrm{rpm}$ and no extra weight was put on the cylinders. Cutting measures were calculated to compensate for the shrinkage induced by sintering. After cutting, the two surfaces of each test specimen were polished with \#150,\#400, \#600, $\# 1200$, and \#2000 grit waterproof abrasive papers to remove any irregularities introduced by cutting.

\section{Shading procedures}

The specimens were divided into two subgroups for each zirconia type; non-shaded and shaded subgroups. Shaded subgroups were shaded before sintering using aqueous-base, acid-free coloring liquid shade $\mathrm{A}_{2}$ color liquid (Prettau ${ }^{\circledR}$ Anterior Aquarell, Zirkonzahn, Taufers, Italy). Each specimen was immersed solely for 10 seconds in a dipping container and time was calibrated using a stopwatch according to the manufacturer recommendations. The specimens were removed from the coloring liquid with a pair of plastic tweezers and hung for 30 seconds in a vertical position to allow dropping of excess liquid traces before being placed on a non-absorbable surface. The specimens were placed for 20 min under an infrared drying lamp (Zirkonlamp 250, Taufers, Italy), following the manufacturer's instructions.

\section{Sintering of the specimens}

The specimens were sintered according to the temperature profile provided by the manufacturer as shown in the following table (Table 1):

TABLE (1) Temperature sintering profile of partially and fully stabilize zirconia specimens.

\begin{tabular}{|c|c|c|c|c|}
\hline Brand name & Temperature & Heating rate & $\begin{array}{c}\text { Isothermal holding } \\
\text { time (min) }\end{array}$ & $\begin{array}{c}\text { Cooling rate } \\
\left({ }^{\circ} \mathrm{C} / \mathbf{m i n}\right)\end{array}$ \\
\hline PSZ (Prettau $\left.{ }^{\circledR}\right)$ & $1600^{\circ} \mathrm{C}$ & $5^{\circ} \mathrm{C} / \mathrm{min}$ & $120 \mathrm{~min}$ & $5^{\circ} \mathrm{C} / \mathrm{min}$ \\
\hline FSZ $\left(\right.$ Prettau ${ }^{\circledR}$ Anterior) & $1500^{\circ} \mathrm{C}$ & $5^{\circ} \mathrm{C} / \mathrm{min}$ & $120 \mathrm{~min}$ & $5^{\circ} \mathrm{C} / \mathrm{min}$ \\
\hline
\end{tabular}




\section{Specimens cleaning}

The final dimensions of the specimens $(12 \mathrm{~mm}$ width $\times 1 \mathrm{~mm}$ thickness $\pm 0.01 \mathrm{~mm}$ ) were measured using digital caliper (Absolute Digimatic Caliper; Mitutoyo Corp, China). The specimens were cleaned ultrasonically in distilled water for $10 \mathrm{~min}$ (Quantrex 90, L\&R Ultrasonics Manufacturing, Kearny, NJ, USA). Each specimen was air-dried for 20 seconds before testing.

\section{Autoclaving-induced LTD (hydrothermal aging)}

Hydrothermal aging (LTD) test as a function of time for the shaded and non-shaded specimens were performed according to the ISO 13356:2008 recommendations, through autoclave (Mammooth superior B Type Vacum Autoclave, DB dental equipment Co., Ltd. UK) processing at $134^{\circ} \mathrm{C}$ at a water partial pressure of 2-3 bars for 5 hours. It is commonly accepted that 1 hour of treatment under these conditions corresponds roughly to a $2-4$ years of exposure in vivo ${ }^{[18]}$.

\section{Microstructural analysis:}

\section{- X-ray diffractometer (XRD):}

Volume fractions of monoclinic phase of crystalline structure of the specimens were measured with X-ray diffraction (XRD-6100 XRD, Diffractometer, Model: GNR APD-2000 PRO, EA Almelo, Netherlands). Each specimen was centered in the sample holder, fixed by rubber cement and placed in the diffractometer so that the radiation beam was directed exactly at the center of the disc, then subjected to $\mathrm{Cu} \mathrm{K}$ alpha radiation with a range of $28^{\circ}-36^{\circ}$, a step size of $0.02^{\circ}$ and the scan time per step was $10 \mathrm{sec}-$ onds. The monoclinic volume fraction $(\mathrm{Vm})$ was calculated using the equation proposed by Toraya and expressed in the following equation ${ }^{[19]}$.

$$
\mathrm{V}_{\mathrm{m}}=\frac{1.311 \mathrm{X}_{\mathrm{m}}}{1+0.311 \mathrm{X}_{\mathrm{m}}}
$$

The monoclinic phase mass fraction is expressed as the percentage of tetragonal phase that was transformed to the monoclinic phase. Relative amounts of monoclinic and tetragonal phases were determined using the expression proposed by Garvie and Nicholson in the following Fraction monoclinic equation ${ }^{[20]}$ :

$$
\mathrm{X}_{\mathrm{m}}=\frac{\mathrm{I}^{\mathrm{m}}{ }_{(-111)}+\mathrm{I}^{\mathrm{m}}{ }_{(111)}}{\mathrm{I}_{(-111)}^{\mathrm{m}}+\mathrm{I}^{\mathrm{m}}{ }_{(111)}+\mathrm{I}^{\mathrm{t}}{ }_{(101)}}
$$

Where $\mathrm{I}^{\mathrm{m}}$ and $\mathrm{I}^{\mathrm{t}}$ are the integrated intensities of monoclinic and tetragonal phases, respectively.

\section{- Atomic force microscope (AFM):}

Three representative specimens from each subgroup were randomly selected, and then thermally etched for 30 minutes at $50^{\circ} \mathrm{C}$ below its sintering temperature with a heating rate of $25^{\circ} \mathrm{C} /$ min to delineate grain boundaries and analyzed using AFM in non-contact mode to examine the changes in the crystal structure after shading and/ or aging ${ }^{[21]}$.

\section{Translucency evaluation:}

Translucency were evaluated using Reflective spectrophotometer, measurements were made according to the CIE L*a*b* color space relative to the CIE standard illuminant D65 in the range of visible wavelengths of 400 to $700 \mathrm{~nm}$ at 10 $\mathrm{nm}$ intervals according to ISO 28642 [22] Each specimen was measured three consecutive times by the same practitioner and mean values for $\mathrm{L}^{*}, \mathrm{a}^{*}$, and $b^{*}$ co-ordinates were recorded. The TP value was determined by calculating the color differences of the specimen over a white or black background with the following equation:

$$
\left[\left(\mathrm{L}^{* \mathrm{~B}}-\mathrm{L}^{* \mathrm{~W}}\right)^{2}+\left(\mathbf{a}^{* \mathrm{~B}}-\mathbf{a}^{* \mathrm{~W}}\right)^{2}+\left(\mathbf{b}^{* \mathrm{~B}}-\mathbf{b}^{* \mathrm{~W}}\right)^{2}\right]^{1 / 2}
$$

Where $\mathrm{B}$ is the color coordinates over a black background and $\mathrm{W}$ is the coordinate over a white background. L* refers to brightness, $\mathrm{a}^{*}$ refers to red-green, and $b^{*}$ refers to yellow- blue. Lower TP values correspond to materials with lower translucency, whereas higher TP values correspond to materials with higher translucency. 
The contrast ratios were measured from the luminous reflectance $(\mathrm{Y})$ of the specimens with a black (Yb) and a white background (Yw) according to the following equation:

\section{$\mathbf{C R}=\mathbf{Y b} / \mathbf{Y w}$}

\section{Statistical Analysis}

The data were collected and tabulated and statistically analyzed by an IBM compatible personal computer with SPSS statistical package version 20 (SPSS Inc. Realesed 2011. IBM SPSS statistics for windows, version 20.0, Armnok, NY: IBM Corp.).

\section{RESULTS}

Without aging the monoclinic phase could not be detected by XRD for PSZ and FSZ. After aging, the monoclinic phase on the surface was detected by XRD. The results are summarized in (Table 2).

TABLE (2) Descriptive analysis of the studied aged groups according to the amount of monoclinic transformation $\%$.

\begin{tabular}{|c|c|c|}
\hline & \multirow{2}{*}{$\begin{array}{l}\text { Amount of monoclinic } \\
\text { transformation }\end{array}$} & $1 \mathrm{~mm}$ \\
\hline & & Mean \pm SD \\
\hline \multirow{2}{*}{ N } & Non-shaded-aged & $6.50 \pm 0.82$ \\
\hline & Shaded-aged & $3.58 \pm 0.72$ \\
\hline \multirow{2}{*}{ N } & Non-shaded-aged & $13.47 \pm 0.86$ \\
\hline & Shaded-aged & $9.47 \pm 0.73$ \\
\hline
\end{tabular}

Based on the calculations, the non- shaded aged specimens showed significantly higher monoclinic fraction than shaded, aged specimens. In addition, overall PSZ specimens have lower monoclinic fractions than FSZ in all groups.

Changes in the microstructure of the zirconia specimens are shown in (Figure 1); surface uplifts presenting on the grains due to $\mathrm{t} \rightarrow \mathrm{m}$ transformation progressed along the grain boundaries, thereby inducing a clear coalescence of the grains.

The highest translucency parameter mean value was recorded for control group of FSZ (13.46 \pm 1.76 ), the lowest value was recorded for shaded, aged PSZ groups $(8.12 \pm 0.54)$. For PSZ there was significant reduction in the translucency parameter (TP) after shading in both groups with and without aging. Aging alone reduced the TP but the reduction was not statistically significant. While for FSZ aging and shading resulted in a significant decrease in the translucency parameter (TR) in all subgroups $(\mathrm{P} \leq 0.05)$.

The highest contrast ratio mean value was recorded for shaded, aged PSZ group $(0.94 \pm 0.04)$ the lowest value was recorded for control group of FSZ $(0.69 \pm 0.03)$. For PSZ aging and shading resulted in a significant increase in the contrast ratio (CR) $(\mathrm{P} \leq 0.05)$ in shaded, non- aged groups and shaded, aged groups but not for non-shaded, aged group the increase was not statistically significant. While for FSZ there was statistically significant increase in the contrast ratio $(\mathrm{CR})$ in all subgroups $(\mathrm{P} \leq 0.05)$.

TABLE (3) Comparing of translucency parameter TP and contrast ratio CR before and after shading and / or aging between different studied groups.

\begin{tabular}{|c|c|c|c|c|c|}
\hline & & \multicolumn{2}{|c|}{ Contrast Ratio } & \multicolumn{2}{|c|}{ Translucency Parameter } \\
\hline & Zirconia Groups & Mean \pm SD & $\mathrm{p}$ value & Mean \pm SD & $\mathrm{p}$ value \\
\hline \multirow{4}{*}{$\underset{\mathscr{2}}{\tilde{2}}$} & Control & $0.81 \pm 0.02^{a}$ & & $9.55 \pm 0.33^{\mathrm{a}}$ & \\
\hline & Non-shaded-aged & $0.83 \pm 0.02^{a}$ & 0.788 & $9.42 \pm 0.42^{\mathrm{a}}$ & 1.00 \\
\hline & Shaded-non aged & $0.91 \pm 0.02^{b}$ & $<0.001^{*}$ & $8.40 \pm 0.40^{\mathrm{b}}$ & $<0.001^{*}$ \\
\hline & Shaded-aged & $0.94 \pm 0.04^{\mathrm{b}}$ & $<0.001^{*}$ & $8.12 \pm 0.54^{b}$ & $<0.001^{*}$ \\
\hline \multirow{4}{*}{ N } & Control & $0.69 \pm 0.03^{c}$ & & $13.46 \pm 1.176^{\mathrm{c}}$ & \\
\hline & Non-shaded-aged & $0.73 \pm 0.03^{\mathrm{d}}$ & $<0.001^{*}$ & $12.48 \pm 0.70^{\mathrm{d}}$ & $<0.001^{*}$ \\
\hline & Shaded-non aged & $0.80 \pm 0.02^{\mathrm{a}}$ & $<0.001^{*}$ & $12.39 \pm 0.96^{\mathrm{d}, \mathrm{e}}$ & $<0.001^{*}$ \\
\hline & Shaded-aged & $0.81 \pm 0.01^{\mathrm{a}}$ & $<0.001^{*}$ & $12.01 \pm 0.74^{\mathrm{e}}$ & $<0.001^{*}$ \\
\hline
\end{tabular}




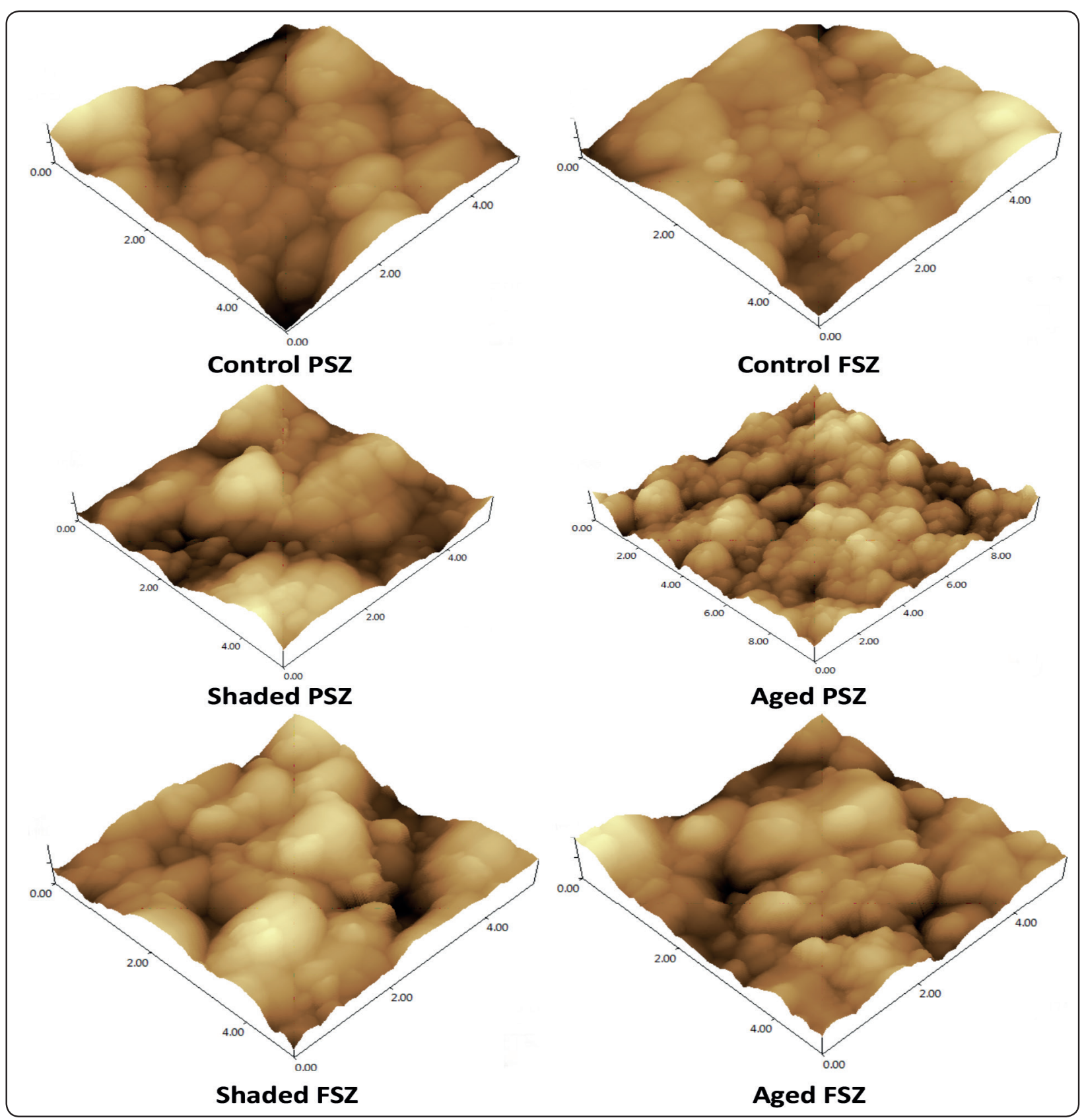

Fig. (1) Representative AFM images of the tested specimens after shading and aging. 


\section{DISCUSSION}

The stabilized zirconia polycrystals tend to degrade in a process called aging (LTD), in which stabilizing oxides are lost from the material structure in humid environment and at room temperatures. This causes the tetragonal to monoclinic phase transformation, resulting in cracking, loss of structural integrity and lowering the mechanical properties of the material. Monolithic zirconia restorations are directly exposed to the intraoral environment because they are not veneered by a ceramic layer. This exposure might triggers (LTD) in this material. In addition, the alumina content of monolithic zirconia is reduced to enhance translucency when compared with conventional zirconia. As alumina is responsible for the resistance to low temperature degradation. Thus, monolithic zirconia may be more sensitive to (LTD) ${ }^{[23]}$.

Translucency is an important parameter in matching the appearance of the natural tooth and was identified as one of the primary factor in controlling esthetics and a critical consideration in the selection of materials. It is addressed by diminishing the opacity of Y-TZP by means of different strategies to eliminate or decrease light-scattering sources ${ }^{[24]}$. One of these strategies is the use of fully stabilized zirconia (FSZ), which has improved translucency due to the increase in cubic phase concentration. In contrast to tetragonal grain in PSZ, scattering is reduced because cubic crystals have an isotropic refractive index ${ }^{[25,26]}$.

Zirconia should be colored to replicate tooth structures ${ }^{[27]}$. Shading methods relies on the infiltration of solutions containing metal-salts applied to the zirconia material in its pre sintered stage after milling process ${ }^{[28,29]}$. These metalsalts interact with the zirconia particles through crystallographic and microstructural changes that may influence the physical and optical properties of zirconia material which was evaluated in the present study. Two types of color liquid are available: aqueous and acid-based; as acid-based liquids decrease the hardness of zirconia, so aqueous-based liquid was used in our study ${ }^{[30]}$. The shade $\mathrm{A}_{2}$ was used because it is the universal color and the most common selected shade ${ }^{[31]}$.

Aging of zirconia ceramics is usually conducted in steam chambers or autoclaves, where the temperature, elapsed time, and pressure of water vapor are the controlled variables. Predictions of lifetime are based on accelerated aging treatments. In the present study, zirconia specimens were subjected to accelerated artificial aging procedure according to the ISO 13356 recommendations ${ }^{[32]}$, through autoclave processing at $134^{\circ} \mathrm{C}$ at a water partial pressure of 2-3 bars for 5 hours. It is suggested that these parameters reproduced degradation equivalent to $15-20$ years at $37^{\circ} \mathrm{C}^{[33]}$.

$\mathrm{X}$-ray diffraction (XRD) was used to examine the surface phase transformation of zirconia by measuring the phase fraction evolution by diffraction of the x-ray beam. The volume of zirconia polycrystalline is influenced by the incidence angles of x-ray beam which small incidence angles give information at the near-surface that's why $28^{\circ}-36^{\circ}$ was used because this portion of the pattern covered the location of the highest peaks of the tetragonal (101) and monoclinic (111) and (-111) phases of the zirconia phase. This technique can be used as the first step to investigate the aging sensitivity of zirconia ${ }^{[34]}$.

Quantitative color match performance of esthetic material is usually determined by the Commission Internationale de L'Eclairage (CIE) L*a*b*. Translucency evaluation was evaluated by calculating contrast ratio (CR) and translucency parameter (TP). Contrast ratio has been selected in the present study in order to easily compare results with the most recent literature. $\mathrm{CR}$ is the ratio of the reflectance of a specimen over a black backing to that over a white backing of a known reflectance, and is an estimate of opacity ${ }^{[35]}$. 
Translucency parameter (TP) which is defined as the color difference of a material (of uniform thickness) between colors reflected against black and white backgrounds was developed to relate translucency with human visual perception ${ }^{[36]}$.

The control specimens (non-shaded, non-aged) of PSZ and FSZ did not have any monoclinic phase. After aging monoclinic phase was detected; this result agreed with Shen et al., 2019 who found that when the PSZ zirconia specimens were subjected to aging, the monoclinic phase on the surface was detected by XRD ${ }^{[37]}$.

In the current study, the results did not come in agreement with Pereia et al., ${ }^{[38]}$ and Ghodiset et al. ${ }^{[39]}$ who stated that FSZ, presenting tetragonal and cubic crystals on its microstructure, being totally inert to the aging in autoclave; without any $\mathrm{t} \rightarrow \mathrm{m}$ phase transformation when aged.

The shaded, aged specimens showed significantly lower monoclinic fraction than non-shaded, aged specimens. In addition, overall PSZ specimens have lower monoclinic fractions than FSZ in all subgroups; the coloring solution lead to more stabilization of stabilized zirconia hence less transformation occurred. In agreement with Keplan et al., 2018 who showed that the colored Y-TZP showed a better resistance to LTD than the non-colored Y-TZP after aging as a result of less transformation from the tetragonal to the monoclinic phase ${ }^{[40]}$.

The present results also come in agreement with De souza et al. ${ }^{[41]}$ and Kelch et al., ${ }^{[42]}$, who analyzed the influence of hydrothermal aging on zirconia and stated that hydrothermal aging affects monoclinic phase content and surface topography.

The topographic analysis depicts different crystalline grain sizes of both zirconia types. Both microstructures are quite homogenous, while a bimodal appearance is found in FSZ specimens, where the grain size was much bigger. These results were consistent with Camposilvan et al., ${ }^{[43]}$.
The present results agreed with Kim et al., 2019 regarding atmoic force microscope results as they found that after hydrothermal aging for $5 \mathrm{~h}$, the $\mathrm{t} \rightarrow \mathrm{m}$ transformation could be clearly seen with related surface uplifts presenting on the ceramic grains, the transformation progressed mainly along the grain boundaries, thereby inducing to a clear coalescence of the grains ${ }^{[44]}$.

Results of the present study coincide with Limsamai et al. ${ }^{[45]}$ and Amat et al. ${ }^{[46]}$ who concluded that autoclave aging promoted grain pull-out in the microstructure due to $\mathrm{t} \rightarrow \mathrm{m}$ transformation that initiated at the surface layer of zirconia and potentially grew into the bulk of the material.

The FSZ had higher TP and lower CR than PSZ zirconia, this finding could be attributed to the differences in yttria content, percentage of chemical impurities, and different zirconia's grain size. In FSZ; greater yttria content leads to an increase of the amount of cubic phase and subsequently, the translucency. The cubic phase in contrast to tetragonal grain, decreases scattering because cubic crystals have an isotropic refractive index. In contrast to that tetragonal zirconia crystal which is optically anisotropic, prevents light scattering from the grain boundaries ${ }^{[47]}$.

Another reason for the different translucency between PSZ and FSZ may be due to the different sintering protocols. Differences in sintering conditions affect the porosity, grain size and can thereby influence the translucency ${ }^{[48]}$. Previous studies observed an impact of sintering parameters of zirconia materials on contrast ratio values and reported that higher sintering temperatures/times led to decreased contrast ratio values. This observation cannot be confirmed by the results of the present study. As PSZ specimens were sintered at $1600^{\circ} \mathrm{C}$. However, the highest contrast ratio was recorded by it. Therefore, it can be assumed that other factors might lead to a positive influence on the contrast ratio like differences in grain size, amount of porosity or the discontinuity of refractive indices at 
the grain boundary are the primary factors affecting the transparency of polycrystalline ceramics ${ }^{[49,50]}$.

The present result was partially coincided with Sulaiman et al. ${ }^{[4]}$ who investigated the effects of shading on the TP values of FSZ versus PSZ and reported a significant decrease in the translucency of FSZ after shading but they stated that shading produced no significant effect on the translucency of PSZ which was not coincide with our results. They attributed this finding to the larger grains and grain boundaries of FSZ that may have led to an increase in coloring liquid intake. Thus, more light photons can be absorbed because of the chemical nature of the solution, resulting in reduced translucency ${ }^{[51]}$.

The effects of shading procedure on the translucency of dental zirconia have been investigated in previous study ${ }^{[52]}$ which evaluated the translucency of shaded zirconia and reported significant differences among the specific shades. However, other studies disagreed with the present results as they reported no significant effect of shading via infiltration technique on the crystal structure of Y-TZP and the TP values and hence the translucency of zirconia on translucency of zirconia ${ }^{[53-56]}$.

For PSZ and FSZ there was a significant increase in $\mathrm{CR}$ and significant decrease in TP after aging this explained by Shen et al., 2019 who stated that hydrothermal aging may alter the crystal structure of Y-TZP and induce reactions within the grain boundaries, thus affecting the transmission of light. The co-existence of different phases (monoclinic/ tetragonal/ cubic) after aging may have contributed to increase the difference between the refractive indices of the various phases, and hence to reduce the translucency ${ }^{[37]}$.

Awad et al., ${ }^{[57]}$ stated that the presence of steam exposure associated with autoclaving accelerates the tetragonal to monoclinic transformation for zirconia. This treatment caused the formation of monoclinic phase with concomitant surface roughness to increase; which caused an increase in light scattering and reflection and thereby a decrease in translucency. This is confirmed by the strong inverse correlation between roughness and translucency which was agreed to our results.

The results presented here agreed with Alghazzawi et al., ${ }^{[31]}$ who concluded that the surface roughness change after aging was due to tetragonal to monoclinic transformation, which increased surface roughness, light scattering, and reflection. These changes will contribute to a decrease of TP and increase in CR. Furthermore, there was cubic phase in the microstructure of FSZ; this phase makes the zirconia more sensitive to aging and, therefore, causes more tetragonal to monoclinic transformation ${ }^{[58]}$.

Present results coincide with Kurt et al., ${ }^{[59]}$ and other studies ${ }^{[30,60-68]}$ who evaluated the effect of hydrothermal aging on the translucency of zirconia and found that stabilized zirconia decreased significantly after aging. As the pores formed after aging causes an increase in the scattering of incident light that decreases translucency. Furthermore, the presence of cubic zirconia accelerates the $\mathrm{t} \rightarrow \mathrm{m}$ transformation, as the cubic grains are larger than the tetragonal ones and pump the $\mathrm{Y}_{2} \mathrm{O}_{3}$ out of the $t$ phase. The tetragonal grains neighboring the c phase are thus depleted in $\mathrm{Y}_{2} \mathrm{O}_{3}$ and act as preferential nucleation sites for aging ${ }^{[33]}$.

When comparing the translucency of different materials, data should not be evaluated only from a statistically viewpoint, as the statistically significance parameter alone could not be representative of the clinical perception of translucency. Concerning CR, Walczak et al., ${ }^{[69]}$ stated that small differences in translucency ( $<0.06$ to 0.07 ) measured with CR are mostly undetectable by the human eye. Thus, even statistically significant differences would most likely not clinically detectable, for shaded, aged group of PSZ and shaded, non-aged and shaded, aged groups of FSZ were higher than 0.07 which could be detected clinically. 
Conversely for CR, the limit of clinical acceptability for TP has not yet been identified, and it is uncertain whether the differences reported could be clinically relevant, even if the correlation between $\mathrm{CT}$ and TP temporarily supports the same conclusions ${ }^{[70,71]}$.

\section{CONCLUSION}

The null hypothesis was rejected as Shading and artificial aging for PSZ and FSZ cause superficial modifications of the crystal structure coupled with tetragonal to monoclinic phase transformation resulted in significant effect in decreasing the translucency parameter and increasing the contrast ratio which in turn affect the optical properties of theses materials.

\section{REFERENCES}

1. Sailer I, Makarov NA, Thoma DS, Zwahlen M, Pjetursson BE. All-ceramic or metal-ceramic tooth-supported fixed dental prostheses (FDPs)? A systematic review of the survival and complication rates. Dental Materials 2015; 31(6):603-23.

2. Pihlaja J, Näpänkangas R, Raustia A. Outcome of zirconia partial fixed dental prostheses made by predoctoral dental students: A clinical retrospective study after 3 to 7 years of clinical service. Journal of Prosthetic Dentistry 2016; 116(1):40-6.

3. Chevalier J, Gremillard L, Virkar AV, Clarke DR. The tetragonal-monoclinic transformation in zirconia: lessons learned and future trends. Journal of the American Ceramic Society 2009; 92(9):1901-20.

4. Sulaiman TA, Abdulmajeed AA, Donovan TE, Vallittu PK, Närhi TO, Lassila LV. The effect of staining and vacuum sintering on optical and mechanical properties of partially and fully stabilized monolithic zirconia. Dental Materials Journal 2015; 34(5):605-10.

5. Della Bona A, Nogueira AD, Pecho OE. Optical properties of CAD-CAM ceramic systems. Journal of Dentistry 2014; 42(9):1202-9.

6. Barizon KT, Bergeron C, Vargas MA, Qian F, Cobb DS, Gratton DG, et al. Ceramic materials for porcelain veneers: part II. Effect of material, shade, and thickness on translucency. Journal of Prosthetic Dentistry 2014; 112(4):864-70.
7. Turgut S, Bagis B, Ayaz EA, Korkmaz FM, Ulusoy $\mathrm{KU}$, Bagis YH. How will surface treatments affect the translucency of porcelain laminate veneers?. Journal of Advanced Prosthodontics 2014; 6(1):8-13.

8. Rondoni D. Zirconia: Some practical aspects from the technologist's point of view. International Journal of Esthetic Dentistry 2016; 11(2):270-4.

9. Lughi V, Sergo V. Low temperature degradation-agingof zirconia: A critical review of the relevant aspects in dentistry. Dental Materials 2010; 26(8):807-20.

10. Camposilvan E, Marro FG, Mestra A, Anglada M. Enhanced reliability of yttria-stabilized zirconia for dental applications. Acta Biomaterialia 2015; 17:36-46.

11. Shahmiri R, Standard OC, Hart JN, Sorrell CC. Optical properties of zirconia ceramics for esthetic dental restorations: A systematic review. Journal of Prosthetic Dentistry 2018; 119(1):36-46.

12. Alghazzawi TF, Lemons J, Liu PR, Essig ME, Bartolucci AA, Janowski GM. Influence of low-temperature environmental exposure on the mechanical properties and structural stability of dental zirconia. Journal of Prosthodontics 2012; 21(5):363-9.

13. Flinn BD, deGroot DA, Mancl LA, Raigrodski AJ. Accelerated aging characteristics of three yttria-stabilized tetragonal zirconia polycrystalline dental materials. Journal of Prosthetic Dentistry 2012; 108(4):223-30.

14. Flinn BD, Raigrodski AJ, Singh A, Mancl LA. Effect of hydrothermal degradation on three types of zirconias for dental application. Journal of Prosthetic Dentistry 2014; 112(6):1377-84

15. Kim H-T, Han J-S, Yang J-H, Lee J-B, Kim S-H. The effect of low temperature aging on the mechanical property \& phase stability of Y-TZP ceramics. Journal of Advanced Prosthodontics 2009; 1(3):113-7.

16. Kohorst P, Borchers L, Strempel J, Stiesch M, Hassel $\mathrm{T}$, Bach F-W, et al. Low-temperature degradation of different zirconia ceramics for dental applications. Acta Biomaterialia 2012; 8(3):1213-20.

17. Nakamura K, Harada A, Kanno T, Inagaki R, Niwano $\mathrm{Y}$, Milleding $\mathrm{P}$, et al. The influence of low-temperature degradation and cyclic loading on the fracture resistance of monolithic zirconia molar crowns. Journal of the Mechanical Behavior of Biomedical Materials 2015; 47:49-56. 
18. International Organization for Standardization. ISO 13356:2008. Implants for surgery-Ceramic materials based on yttria-stabilized tetragonal zirconia (Y-TZP).

19. Toraya H, Yoshimura M, Somiya S. Calibration curve for quantitative analysis of the Monoclinic - Tetragonal $\mathrm{ZrO}_{2}$ system by X-ray diffraction. Journal of the American Ceramic Society 1984; 67(6):119-21.

20. Garvie R, Hannink R, Pascoe R. Ceramic steel? Nature 1975; 258(5537):703-5

21. Deville S, Chevalier J, El Attaoui H. Atomic force microscopy study and qualitative analysis of martensite relief in zirconia. Journal of the American Ceramic Society 2005; 88(5):1261-7.

22. International Organization for Standardization. ISO 28642: 2016 Dentistry-Guidance on Colour Measurement.

23. Bergamo E, da Silva WJ, Cesar PF, Del Bel Cury AA. Fracture Load and Phase Transformation of Monolithic Zirconia Crowns Submitted to Different Aging Protocols. Operative dentistry 2016; 41(5):118-30.

24. Homaei E, Farhangdoost K, Tsoi JKH, Matinlinna JP, Pow EHN. Static and fatigue mechanical behavior of three dental CAD/CAM ceramics. Journal of Mechanical Behavior of Biomedical Materials 2016; 59:304-13.

25. Denry I, Kelly J. Emerging ceramic-based materials for dentistry. Journal of Dental Research 2014; 93(12): 1235-42.

26. Stawarczyk B, Frevert K, Ender A, Roos M, Sener B, Wimmer T. Comparison of four monolithic zirconia materials with conventional ones: Contrast ratio, grain size, four-point flexural strength and two-body wear. Journal of the Mechanical Behavior of Biomedical Materials 2016; 59:128-38.

27. Vichi A, Louca C, Corciolani G, Ferrari M. Color related to ceramic and zirconia restorations: a review. Dental Materials 2011; 27(1):97-108.

28. Mahshid M, Berijani N, Sadr SJ, Tabatabaian F, Homayoon SS. Effect of coloring-by-dipping on microtensile bond strength of zirconia to resin cement. Journal of Dentistry 2015; 12(6):414-23.

29. Sedda M, Vichi A, Carrabba M, Capperucci A, Louca C, Ferrari M. Influence of coloring procedure on flexural resistance of zirconia blocks. Journal of Prosthetic Dentistry 2015; 114(1):98-102.
30. Nam J-Y, Park M-G. Effects of aqueous and acid-based coloring liquids on the hardness of zirconia restorations. Journal of Prosthetic Dentistry 2017; 117(5):662-8.

31. Alghazzawi TF. The effect of extended aging on the optical properties of different zirconia materials. Journal of Prosthodontic Research 2017; 61(3):305-14.

32. International Organization for Standardization. ISO 13356:2008. Implants for surgery-Ceramic materials based on yttria-stabilized tetragonal zirconia (Y-TZP).

33. Chevalier J, Gremillard L, Deville S. Low-temperature degradation of zirconia and implications for biomedical implants. Annual Review of Material Research 2017; 37:1-32.

34. Limsamai N, Pongpruaksa P, Suputtamongkol K. The effect of accelerated aging on phase transformation and flexural strength of conventional and translucent zirconiabased dental ceramics. Mahidol Dental Journal 2019; 39(2):99-105.

35. Carrabba M, Keeling AJ, Aziz A, Vichi A, Fonzar RF, Wood D, et al. Translucent zirconia in the ceramic scenario for monolithic restorations: A flexural strength and translucency comparison test. Journal of Dentistry 2017; 60:70-6.

36. Nogueira AD, Della Bona A. The effect of a coupling medium on color and translucency of CAD-CAM ceramics. Journal of Dentistry 2013; 41:18-23.

37. Shen J, Xie H, Wu X, Yang J, Liao M, Chen C. Evaluation of the effect of low-temperature degradation on the translucency and mechanical properties of ultratransparent 5Y-TZP ceramics. Ceramics International 2019; 46(1):553-9.

38. Pereira GK, Guilardi LF, Dapieve KS, Kleverlaan CJ, Rippe MP, Valandro LF. Mechanical reliability, fatigue strength and survival analysis of new polycrystalline translucent zirconia ceramics for monolithic restorations. Journal of the Mechanical Behavior of Biomedical Materials 2018; 85:57-65.

39. Ghodsiet S, Jafarian Z. A Review on Translucent Zirconia. European Journal of Posthodontics and Restorative Dentistry 2018; 26(2):62-74.

40. Kaplan M, Park J, Kim SY, Ozturk A. Production and properties of tooth-colored yttria stabilized zirconia ceramics for dental applications. Ceramics International 2018; 44(2):2413-8 
41. De Souza GM, Zykus A, Ghahnavyeh RR, Lawrence SK, Bahr DF. Effect of accelerated aging on dental zirconiabased materials. Journal of the Mechanical Behavior of Biomedical Materials 2017; 65:256-63.

42. Kelch M, Schulz J, Edelhoff D, Sener B, Stawarczyk B. Impact of different pretreatments and aging procedures on the flexural strength and phase structure of zirconia ceramics. Dental Materials 2019; 35(10):1439-49.

43. Camposilvan E, Leone R, Gremillard L, Sorrentino R, Zarone F, Ferrari M, et al. Aging resistance, mechanical properties and translucency of different yttria-stabilized zirconia ceramics for monolithic dental crown applications. Dental Materials 2018; 34(6):879-90.

44. Kim S-H, Choi Y-S. Changes in properties of monolithic and conventional zirconia during aging process. Mechanics of Materials 2019; 138:103159.

45. Amat NF, Muchtar A, Amril MS, Ghazali MJ, Yahaya N. Effect of sintering temperature on the aging resistance and mechanical properties of monolithic zirconia. Journal of Materials Research and Technology 2019; 8(1):1092-101.

46. Limsamai N, Pongpruaksa P, Suputtamongkol K. The effect of accelerated aging on phase transformation and flexural strength of conventional and translucent zirconia-based dental ceramics. Mahidol Dental Journal 2019; 39(2):99-105.

47. Sulaiman TA, Abdulmajeed AA, Donovan TE, Ritter AV, Vallittu PK, Närhi TO, et al. Optical properties and light irradiance of monolithic zirconia at variable thicknesses. Dental Materials 2015; 31(10):1180-7.

48. Zhuang Y, Zhu Z, Jiao T, Sun J. Effect of aging time and thickness on low-temperature degradation of dental zirconia. Journal of Prosthodontics 2019; 28(1):404-10.

49. Stawarczyk B, Özcan M, Hallmann L, Ender A, Mehl A, Hämmerlet $\mathrm{CH}$. The effect of zirconia sintering temperature on flexural strength, grain size, and contrast ratio. Clinical Oral Investigations 2013; 17(1):269-74.

50. Sen N, Sermet IB, Cinar S. Effect of coloring and sintering on the translucency and biaxial strength of monolithic zirconia. Journal of Prosthetic Dentistry 2018; 119(2):308-12.

51. Nakamura K, Harada A, Ono M, Shibasaki H, Kanno T, Niwano Y, et al. Effect of low-temperature degradation on the mechanical and microstructural properties of tooth-colored 3Y-TZP ceramics. Journal of the Mechanical Behavior of Biomedical Materials 2016; 53:301-11.
52. Spyropoulou P-E, Giroux EC, Razzoog ME, Duff RE. Translucency of shaded zirconia core material. Journal of Prosthetic Dentistry 2011; 105(5):304-7.

53. Kurtulmus-Yilmaz S, Ulusoy M. Comparison of the translucency of shaded zirconia all-ceramic systems. Journal of Advanced Prosthodontics 2014; 6(5):415-22.

54. Zhang F, Vanmeensel K, Batuk M, Hadermann J, Inokoshi M, Van Meerbeek B, et al. Highly-translucent, strong and aging-resistant 3Y-TZP ceramics for dental restoration by grain boundary segregation. Acta Biomaterialia 2015; 16:215-22.

55. Kaplan M, Park J, Kim SY, Ozturk A. Production and properties of tooth-colored yttria stabilized zirconia ceramics for dental applications. Ceramics International 2018; 44(2):2413-8.

56. Alp G, Subaşı MG, Seghi RR, Johnston WM, Yilmaz B. Effect of shading technique and thickness on color stability and translucency of new generation translucent zirconia. Journal of Dentistry 2018; 73:19-23.

57. Awad D, Stawarczyk B, Liebermann A, Ilie N. Translucency of esthetic dental restorative CAD/CAM materials and composite resins with respect to thickness and surface roughness. Journal of Prosthetic Dentistry 2015; 113(6):534-40

58. Inokoshi M, Vanmeensel K, Zhang F, De Munck J, Eliades G, Minakuchi S, et al. Aging resistance of surface-treated dental zirconia. Dental Materials 2015; 31(2):182-94.

59. Kurt M, Bal BT. Effects of accelerated artificial aging on the translucency and color stability of monolithic ceramics with different surface treatments. Journal of Prosthetic Dentistry 2019; 121(4):712-6.

60. Tong H, Tanaka CB, Kaizer MR, Zhang Y. Characterization of three commercial Y-TZP ceramics produced for their high-translucency, high-strength and high-surface area. Ceramics International 2016; 42(1):1077-85.

61. Fathy SM, El-Fallal AA, El-Negoly SA, El Bedawy AB. Translucency of monolithic and core zirconia after hydrothermal aging. Acta Odontologica Scandinavica 2015; 1(24):86-92.

62. Kanchanavasita W, Triwatana P, Suputtamongkol K, Thanapitak A, Chatchaiganan M. Contrast ratio of six zirconia-based dental ceramics. Journal of Prosthodontics $2014 ; 23(6): 456-61$. 
63. Kim HK, Kim SH, Lee JB, Ha SR. Effects of surface treatments on the translucency, opalescence, and surface texture of dental monolithic zirconia ceramics. Journal of Prosthetic Dentistry 2016; 115(6):773-9.

64. Bagis B, Turgut S. Optical properties of current ceramics systems for laminate veneers. Journal of Dentistry 2013; 41:24-30.

65. Dikicier S, Ayyildiz S, Ozen J, Sipahi C. Effect of varying core thicknesses and artificial aging on the color difference of different all-ceramic materials. Acta Odontologica Scandinavica 2014; 72(8):623-9.

66. Stawarczyk B, Emslander A, Roos M, Sener B, Noack F, Keul C. Zirconia ceramics, their contrast ratio and grain size depending on sintering parameters. Dental Materials Journal 2014; 33(5):591-8.

67. Lee Y-K. Translucency changes of direct esthetic restorative materials after curing, aging and treatment. Restorative Dentistry \& Endodontics 2016; 41(4):239-45.
68. Putra A, Chung K-H, Flinn BD, Kuykendall T, Zheng C, Harada $\mathrm{K}$, et al. Effect of hydrothermal treatment on light transmission of translucent zirconias. Journal of Prosthetic Dentistry 2017; 118(3):422-9.

69. Walczak K, Meißner H, Range U, Sakkas A, Boening K, Wieckiewicz M, et al. Translucency of Zirconia Ceramics before and after Artificial Aging. Journal of Prosthodontics 2019; 28(1):319-24.

70. Pecho OE, Ghinea R, Ionescu AM, de la Cruz Cardona J, Paravina RD, del Mar Pérez M. Color and translucency of zirconia ceramics, human dentine and bovine dentine. Journal of Dentistry 2012; 40:34-40.

71. Barizon KT, Bergeron C, Vargas MA, Qian F, Cobb DS, Gratton DG, et al. Ceramic materials for porcelain veneers. Part I: Correlation between translucency parameters and contrast ratio. Journal of Prosthetic Dentistry 2013; 110(5):397-401. 